\title{
Analisis Kinerja Keuangan berdasarkan Rasio Keuangan pada PT. BPR. Saptacristy Utama
}

\author{
NI LUH KOMANG AYU PRADNYANI, I NYOMAN GEDE USTRIYANA, \\ I GUSTI AYU AGUNG LIES ANGGRENI
}

\author{
Program Studi Agribisnis, Fakultas Pertanian, Universitas Udayana \\ J1. PB. Sudirman Denpasar 80323 \\ E-mail: kemi2529@gmail.com \\ gede_ustriyana@unud.ac.id
}

\begin{abstract}
Analysis of Finece Performance Base on Fund Finance Ratio of PT. BPR. Saptacristy Utama
\end{abstract}

Rural Banks (BPR) is a formal financial institution that has a function as a financial intermediary, especially on the national microfinance system. The study aimed to find out the financial performance of PT. BPR. Saptacristy Utama when it was analyzed based on the financial ratios during the period of 2011 to 2015. Based on the results of the financial analysis, liquidity ratio is categorized good, when viewed from the average cash ratio and the average loans to deposit ratio. The solvency ratio is said to be good, judging by the average capital adequacy ratio. Activity ratio is quite good when viewed from the multiplier leverage ratio and asset utilization ratio that continue to increase. The profitability ratio is classified to be good,as can be seen on the average net profit margin, return on assets and return on equity. PT. BPR. Saptacristy Utama is expected to maintain its financial performance by strengthening its business activities to increase the amount of its assets, the amount of the distribution of funds in the form of loans and the placement of funds in other banks should also be increased, revenue of operations and profits for subsequent years should beincreased, as well as improving sale and service to its customers and prospective customers.

Keywords: rural banks, finance performance, financial ratioanalysis

\section{Pendahuluan}

\subsection{Latar Belakang}

Bank mempunyai peran yang begitu penting dalam masyarakat sebagai penggerak perekonomian. UU No. 7 Tahun 1992 tentang perbankan yang telah diubah menjadi UU No. 10 Tahun 1998 membagi bank dalam dua golongan besar, yaitu Bank Umum dan Bank Perkreditan Rakyat atau yang sering disebut BPR.

Bank Perkreditan Rakyat (BPR) merupakan salah satu lembaga keuangan formal yang memiliki fungsi sebagai lembaga intermediasi keuangan khususnya pada sistem keuangan mikro nasional (Tim Pedoman Akutansi Bank Perkreditan Rakyat 
Bank Indonesia, 2010). Keberadaan BPR telah terbukti sangat dirasakan manfaatnya bagi masyarakat ekonomi kecil dan menegah karena mudah dijangkau oleh mereka. Meskipun saat ini hadir begitu banyak lembaga keuangan mikro baik bank maupun non bank, eksistensi dan keberadaannya telah mendapatkan pengakuan dari masyarakat. Dilihat dari hal ini menilai kinerja keuangan suatu bank menjadi hal yang sangat penting, karena selain dapat menunjukkan bank itu sehat atau tidak juga akan bermanfaat bagi para manajer bank itu sendiri ataupun pihak lain di luar bank yang berkepentingan, baik itu para pelaku investor dan kreditor yang akan menyalurkan modalnya maupun debitur yang akan meminjam dana, selain itu penilaian kinerja bank juga sangat penting dilakukan mengingat oprasi perbankan sangat peka terhadap maju mundurnya perekonomian suatu Negara ( Prasnanugraha, 2007 dalam Maikel dan Stanly, 2015). Analisis rasio keuangan merupakan salah satu metode yang paling sering digunakan untuk mengetahui kinerja keuangan (Handayani,et al, 2012).

PT. BPR. Saptacristy Utama sebagai salah satu bank perkreditan rakyat memegang peranan penting yang cukup strategi bagi perekonomian di daerah terutama dalam mendorong perkembangan usaha mikro, kecil, dan menengah (UMKM).PT. BPR. Saptacristy Utama juga memberikan informasi kondisi keuangan kepada para nasabah untuk memberikan pelayanan yang maksimal. Oleh karena itu secara periodik, PT. BPR. Saptacristy Utama juga melakukan analisis terhadap laporan keuangan bank guna mendapatkan kondisi aktual keuangan bank yang nantinya akan diinformasikan kepada para nasabah dan calon nasabah. Analisis rasio keuangan ini menghubungkan unsur-unsur neraca dan perhitungan laporan rugi laba satu dengan yang lain, dengan cara membandingkan elemen-elemen dari aktiva dan dari elemen-elemen passiva (Sawir, 2003). Melalui analisis rasio keuangan akan diperoleh ukuran - ukuran tentang tingkat likuiditas, solvabilitas, aktivitas dan profitabilitas (Satria, 1993 dalam Ramenayanti, 2016). Hal ini dilakukan agar PT. BPR. Saptacristy Utama dapat menghimpun dan menyalurkan dana kepada masyarakat, agar memperoleh sumber pendapatan utama bank, serta meningkatkan profit yang diharapkan setiap tahunnya.

Menurut Kasmir (2014), laporan keuangan bank merupakan bentuk pertanggungjawaban manajemen terhadap pihak-pihak yang berkepentingan dengan kinerja bank yang dicapai selama periode tertentu. Tujuan laporan keuangan bank adalah untuk memberikan informasi tentang posisi keuangan, kinerja, perubahan ekuitas, arus kas, dan informasi lainnya yang bermanfaat bagi pengguna laporan keuangan dalam rangka membuat keputusan ekonomi serta menunjukkan pertanggungjawaban manajemen atas penggunaan sumber daya yang dipercayakan kepada mereka.

Posisi keuangan pada laporan neraca dan laba rugi pada PT. BPR. Saptacristy Utama per 31 Desember tahun 2011 sampai dengan tahun 2015 mengalami kenaikan dan penurunan. Perkiraan-perkiraan yang mengalami perubahan itu seperti kas, penepatan pada bank lain, total asset, total loans, equity capital, pendapatan non 
operasional dan laba bersih sebelum pajak. Perkiraan-perkiraan yang mengalami peningkatan dan penurunan tersebut dapat dilihat pada Tabel 1 dibawah ini.

Tabel 1.

Perkiraan-perkiraan yang Mengalami Peningkatan dan Penurunan Pada Neraca dan Laporan Laba Rugi PT. BPR. Saptacristy Utama dari Tahun 2011 sampai dengan Tahun 2015 (Ribuan Rp )

\begin{tabular}{|c|c|c|c|c|c|}
\hline \multirow[t]{2}{*}{ Perkiraan } & \multicolumn{5}{|c|}{ Tahun } \\
\hline & 2011 & 2012 & 2013 & 2014 & 2015 \\
\hline Kas & 94.557 & 195.874 & 119.013 & 127.632 & 126.004 \\
\hline $\begin{array}{l}\text { Penempatan Pada } \\
\text { Bank Lain }\end{array}$ & 1.243 .248 & 2.194 .579 & 3.597 .074 & 2.597 .074 & 5.034 .116 \\
\hline Total Asset & 10.395 .347 & 16.637 .102 & 16.959 .260 & 22.802 .362 & $.28 .485,322$ \\
\hline Total Loans & 8.423 .674 & 13.670 .060 & 12.726 .804 & 19.703 .978 & 22.393 .028 \\
\hline Equity Capital & 1.338 .933 & 1.612 .102 & 2.112 .221 & 2.484 .616 & .3 .002 .291 \\
\hline $\begin{array}{ll}\text { Pendapatan } & \text { No } \\
\text { Oprasional } & \end{array}$ & 33.318 & 43.364 & 31.131 & 9.135 & .14 .068 \\
\hline $\begin{array}{l}\text { Laba Bersih } \\
\text { Sebelum Pajak }\end{array}$ & 215.761 & 428.468 & 627.094 & 613.297 & .664 .778 \\
\hline
\end{tabular}

Sumber: Neraca dan Laporan Laba Rugi PT. BPR. Saptacristy Utama

Peningkatan dan penurunan pada perkiraan-perkiraan di atas membuat penulis ingin mengetahui bagaimana manajemen bank dalam mengelola keuangannya ditinjau dari rasio likuiditas, solvabilitas, aktivitas, dan rentabilitas sehingga dapat diketahui kinerja keuangan bank.

Berdasarkan Uraian di atas penulis tertarik untuk melakukan penelitian dengan topik analisis kinerja keuangan berdasarkan rasio keuanganpada PT. BPR Saptacristy Utama tahun 2011 sampai dengan tahun 2015.

\subsection{Tujuan}

Tujuan yang ingin dicapai dalam penelitianini adalah untuk mengetahui bagaimana kinerja keuangan PT. BPR. Saptacristy Utama jika dianalisis berdasarkan rasio keuangan pada periode tahun 2011 sampai dengan tahun 2015.

\section{Metode Penelitian}

\subsection{Lokasi dan Waktu Penelitian}

Penelitian ini dilakukan di PT. BPR. Saptacristy Utama pada bulan Juli 2016. Penentuan lokasi penelitian dilakukan secara purposive dengan dasar pertimbangan: (1) PT.BPR. Saptacristy Utama bersedia untuk diteliti kondisi keuangannya, (2) Dilihat dari faktor akses pengumpulan data, peneliti lebih mudah dalam pengumpulan data karena pihak BPR yang terbuka dalam memberikan data, dan (3) 
Belum ada penelitian mengenai penilaian kinerja keuangan untuk tahun 2011sampai tahun 2015.

\subsection{Jenis dan Sumber Data}

Data yang dikumpulkan dalam penelitian ini adalah data kualitatif dan data kuantitatif. Sumber data terdiri atas data primer dan data skunder.

\subsection{Metode Pengumpulan Data}

Metode pemgumpulan data yang digunakan dalam penelitian ini meliputi dokumentasi, wawancara, dan studi kepustakaan.

\subsection{Informan Kunci}

Dalam penelitian ini, informan kunci yang digunakan adalah berjumlah dua orang yaitu Direktur Utama dan bagian keuangan PT. BPR. Saptacristy Utama.

\subsection{Variabel penelitian dan Metode Analisis Data}

Variabel yang digunakan dalam penelitian ini adalah rasio likuiditas dilihat dari cash ratio dan loan to deposite ratio, rasio solvabilitas dilihat dari capital adequacy ratio, rasio aktivitas dapat dilihat dari laverage multiplier dan assets utilitation, rasio rentabilitas dilihat dari net profit margin, return on asset, dan return on equity. Metode analisis data yang digunakan dalam penelitian ini adalah analisis rasio keuangan dari tahun 2011 sampai dengan tahun 2015, analisis rasio keuangan merupakan suatu perhitungan rasio menggunakan laporan keuangan atau dengan kata lain perhitungan rasio yang menggunakan perbandingan antara satu pos keuangan dengan pos keuangan lainnya untuk mendapatkan hasil atau angka yang akan berfungsi sebagai alat ukur dalam menilai kondisi keuangan dan kinerja (Kasmir, 2004), kemudian dilakukan analisis deskriptif untuk mengetahui faktor-faktor yang mempengaruhi kondisi keuangan PT. BPR. Saptacristy Utama berdasarkan analisis rasio keuangan.

\section{Hasil dan Pembahasan}

\subsection{Kinerja Keuangan PT. BPR. Saptacristy Utama}

Kinerja keuangan PT. BPR. Saptacristy Utama dianalisis dengan mengambil data yang bersumber dari neraca dan laporan laba rugi yang ada pada laporan tahun terakhir, yaitu dari tahun 2011 sampai dengan tahun 2015. Data yang diperoleh dianalisis berdasarkan rasio-rasio keuangan yang dipergunakan bank, yaitu: rasio likuiditas, rasio solvabilitas, rasio aktivitas, dan rasio rentabilitas.

\subsubsection{Rasio likuiditas}

Rasio likuiditas menunjukan kemampuan PT. BPR. Saptacristy Utama dalam memenuhi kewajiban jangka pendeknya tepat waktu, dapat membayar kembali kepada semua deposannya, serta dapat memenuhi permintaan kredit yang diajukan tapa ada penangguhan. Berdasarkan hasil perhitungan rasio likuiditas PT. BPR. 
Saptacristy Utama dari tahun 2011 sampai dengan tahun 2015 dapat dilihat dari nilai cash ratio berkisar antara $16,05 \%$ sampai dengan $26,92 \%$ dan nilai dari loan to deposite ratio berkisar antara $80,15 \%$ sampai dengan $89,50 \%$. Hasil analisis terhadap rasio likuiditas dapat dilihat pada Tabel 2.

Tabel 2.

Perhitungan Analisis Rasio Keuangan Likuiditas PT. BPR. Saptacristy Utama Tahun 2011 sampai dengan Tahun 2015

\begin{tabular}{|c|c|c|c|c|c|c|}
\hline \multirow{2}{*}{ Rasio Likuiditas } & \multicolumn{5}{|c|}{ Tahun } & \multirow{2}{*}{$\begin{array}{l}\text { Rata- } \\
\text { Rata }\end{array}$} \\
\hline & 2011 & 2012 & 2013 & 2014 & 2015 & \\
\hline Cash Ratio & $\begin{array}{l}16,05 \% \\
\text { (Sehat) }\end{array}$ & $\begin{array}{l}17,07 \% \\
\text { (Sehat) }\end{array}$ & $\begin{array}{l}26,92 \% \\
\text { (Sehat) }\end{array}$ & $\begin{array}{l}12,93 \% \\
\text { (Sehat) }\end{array}$ & $\begin{array}{c}21,74 \% \\
\text { (Sehat) }\end{array}$ & $\begin{array}{l}18,94 \% \\
\text { (Sehat) }\end{array}$ \\
\hline Loans To Deposite Ratio & $\begin{array}{l}87,32 \% \\
\text { (Sehat) }\end{array}$ & $\begin{array}{l}89,50 \% \\
\text { (Sehat) }\end{array}$ & $\begin{array}{l}80,15 \% \\
\text { (Sehat) }\end{array}$ & $\begin{array}{l}88,93 \% \\
\text { (Sehat) }\end{array}$ & $\begin{array}{l}84,26 \% \\
\text { (Sehat) }\end{array}$ & $\begin{array}{l}86,03 \% \\
\text { (Sehat) }\end{array}$ \\
\hline
\end{tabular}

Sumber : Diolah dari data primer (2016)

Selama lima tahun terakhir yaitu dari tahun 2011 sampai dengan tahun 2015 nilai cash ratio setiap tahunnya cenderung berfluktuatif. Meskipun berfluktuatif, kenaikan cash ratio lebih besar dari penurunannya. Hal tersebut dikarenakan peningkatan kewajiban lancar sebanding dengan peningkatan liquid asset, sehingga tingkat kemampuan BPR untuk memenuhi kewajiban lancar sesuai dengan yang diharapkan.Kinerja PT. BPR. Saptacristy Utama dilihat dari rata-rata cash ratio pada tahun 2011 sampai dengan tahun 2015 sebesar 18,94\%. Pencapaian presentase nilai rata-rata tersebut berada pada kriteria cash ratio $\geq 4,05 \%$ yang berarti sehat (SK DIR BI Nomor : 30/21/KEP/DIR). Hal ini dapat diartikan bahwa kemampuan PT. BPR. Saptacristy Utama dalam memenuhi kewajiban lancar yang segera harus dipenuhi adalah setiap Rp. 100,00 kewajiban lancar dijamin oleh liquid asset sebesar Rp.18,94.

Selama lima tahun terakhir yaitu dari tahun 2011 sampai dengan tahun 2015 nilai loan to deposite ratio setiap tahunnya cenderung berfluktuatif. Meskipun berfluktuatif, kenaikan loan to deposite ratio lebih besar dari penurunannya. Hal tersebut dikarenakan peningkatan jumlah dana yang diterima sebanding dengan peningkatan total loans, sehingga tingkat kemampuan BPR untuk kembali kewajibannya kepada deposan dan pemilik modal sesuai dengan yang diharapkan.Kinerja PT. BPR. Saptacristy Utama dilihat dari rata-rata loan to deposite ratio pada tahun 2011 sampai dengan tahun 2015 sebesar 86,03\%. Pencapaian presentase nilai rata-rata tersebut berada pada kriteria loan to deposite ratio yaitusebesar $\leq 94,75 \%$ yang berarti sehat (SK DIR BI Nomor : 30/21/KEP/DIR). Hal ini dapat diartikan bahwa kemampuan PT. BPR. Saptacristy Utama dalam membayar kewajiban kepada deposan dan pemilik modal adalah setiap Rp. 100,00 dana yang diterima dijamin oleh total loans sebesar Rp.86,03. 


\subsubsection{Rasio solvabilitas}

Rasio solvabilitas menunjukan kemampuan PT. BPR. Saptacristy Utama dalam memenuhi kewajiban keuangannya, baik kewajiban jangka pendek maupun kewajiban jangka panjang. Rasio ini menyangkut jaminan yang menggukur seberapa jauh PT. BPR. Saptacristy Utama dibiayai oleh pihak luar (kreditur). Berdasarkan hasil perhitungan rasio solvabilitas PT. BPR. Saptacristy Utama dari tahun 2011 sampai dengan tahun 2015 dapat dilihat dari nilai capital adequacy ratio berkisar antara $8,94 \%$ sampai dengan $13,15 \%$. Hasil analisis terhadap rasio likuiditas dapat dilihat pada Tabel 3.

Tabel 3.

Perhitungan Analisis Ratio Keuangan Solvabilitas PT. BPR. Saptacristy Utama Tahun 2011 sampai dengan Tahun 2015

\begin{tabular}{ccccccc}
\hline \multirow{2}{*}{ Rasio Solvabilitas } & \multicolumn{5}{c}{ Tahun } & $\begin{array}{c}\text { Rata- } \\
\text { rata }\end{array}$ \\
\cline { 2 - 6 } & $\mathbf{2 0 1 1}$ & $\mathbf{2 0 1 2}$ & $\mathbf{2 0 1 3}$ & $\mathbf{2 0 1 4}$ & $\mathbf{2 0 1 5}$ & \\
\hline $\begin{array}{c}\text { Capital Adequacy } \\
\text { Ratio }\end{array}$ & $\begin{array}{c}10,47 \% \\
\text { (Sehat) }\end{array}$ & $\begin{array}{c}8,94 \% \\
\text { (Sehat) }\end{array}$ & $\begin{array}{c}13,15 \% \\
\text { (Sehat) }\end{array}$ & $\begin{array}{c}10,57 \% \\
\text { (Sehat) }\end{array}$ & $\begin{array}{c}11,80 \% \\
\text { (Sehat) }\end{array}$ & $\begin{array}{c}10,99 \% \\
\text { (Sehat) }\end{array}$
\end{tabular}

Sumber: Diolah dari data primer (2016)

Selama lima tahun terakhir yaitu dari tahun 2011 sampai dengan tahun 2015 nilai capital adequacy ratio setiap tahunnya cenderung berfluktuatif. Meskipun berfluktuatif, kenaikan capital adequacy ratio lebih besar dari penurunannya. Hal tersebut dikarenakan peningkatan total loans sebanding dengan peningkatan equity capital, sehingga tingkat kemampuan BPR untuk menangulangi kegagalan kredit sesuai dengan yang diharapkan.Kinerja PT. BPR. Saptacristy Utama dilihat dari ratarata capital adequacy ratio pada tahun 2011 sampai dengan tahun 2015 sebesar $10,99 \%$ Pencapaian presentase nilai rata-rata tersebut berada pada kriteria capital adequacy ratio $>8 \%$ yang berarti sehat (SK DIR BI Nomor : 30/21/KEP/DIR). Hal ini dapat diartikan bahwa kemampuan PT. BPR. Saptacristy Utama untuk mejamin kegagalan kredit adalah setiap Rp. 100,00 total loans dijamin oleh permodalan dikurangi aktiva tetapsebesar Rp.10,99.

\subsubsection{Rasio aktivitas}

Rasio aktivitas merupakan rasio yang digunakan untuk mengukur apakah PT. BPR. Saptacristy Utama telah menggunakan semua faktor produksinya dengan tepat guna dan hasil guna. Berdasarkan hasil perhitungan rasio aktivitas PT. BPR. Saptacristy Utama dari tahun 2011 sampai dengan tahun 2015 dapat dilihat dari nilai laverage multiplier berkisar antara 7,76 kali sampai dengan 10,34 kali dan nilai dari asset utilization berkisar antara 9,56\% sampai dengan 12,62\%. Hasil analisis terhadap rasio likuiditas dapat dilihat pada Tabel 4. 
Tabel 4.

Perhitungan Analisis Ratio Keuangan Aktivitas PT. BPR. Saptacristy Utama Tahun 2011 sampai dengan Tahun 2015

\begin{tabular}{|c|c|c|c|c|c|c|}
\hline \multirow[t]{2}{*}{ Rasio Aktivitas } & \multicolumn{5}{|c|}{ Tahun } & \multirow{2}{*}{$\begin{array}{l}\text { Rata- } \\
\text { rata }\end{array}$} \\
\hline & 2011 & 2012 & 2013 & 2014 & 2015 & \\
\hline $\begin{array}{l}\text { Laverage } \\
\text { Multiplier }\end{array}$ & 7,76 Kali & $\begin{array}{c}10,34 \\
\text { Kali }\end{array}$ & 8,03 Kali & 9,18 Kali & 9,48 Kali & 8,96 Kali \\
\hline $\begin{array}{c}\text { Asset } \\
\text { Utilization }\end{array}$ & $9,56 \%$ & $9,85 \%$ & $12,62 \%$ & $10,74 \%$ & $10,19 \%$ & $11,80 \%$ \\
\hline
\end{tabular}

Sumber : Diolah dari data primer (2016)

Selama lima tahun terakhir yaitu dari tahun 2011 sampai dengan tahun 2015 nilai laverage multiplier setiap tahunnya cenderung berfluktuatif. Meskipun berfluktuatif, kenaikan laverage multiplier lebih besar dari penurunannya. Hal tersebut dikarenakan peningkatan equity capital sebanding dengan peningkatan total asset, sehingga tingkat kemampuan BPR untuk mengelola aktiva atau total asset yang dimiliki sesuai harapan.Kinerja PT. BPR. Saptacristy Utama dilihat dari ratarata laverage multiplier pada tahun 2011 sampai dengan tahun 2015 sebesar 8,96 kali. Hal ini dapat diartikan bahwa setiap Rp. 1 total asset yang dikelolaakan di jamin oleh total equity capytal sebesar 8,96 kali.

Selama lima tahun terakhir yaitu dari tahun 2011 sampai dengan tahun 2015 nilai asset utilization setiap tahunnya cenderung berfluktuatif. Meskipun berfluktuatif, kenaikan asset utilization lebih besar dari penurunannya. Hal tersebut dikarenakan peningkatan total icome sebanding dengan peningkatan total asset, sehingga tingkat kemampuan BPR untuk mengelola total asset sesuai dengan yang diharapkan.Kinerja PT. BPR. Saptacristy Utama dilihat dari rata-rata asset utilization pada tahun 2011 sampai dengan tahun 2015 sebesar 11,80\% Hal ini dapat diartikan bahwa kemampuan PT. BPR. Saptacristy Utama untuk menghasilkan total income adalah setiap Rp. 100,00 total asset menghasilkan total income sebesar Rp.11,80.

\subsubsection{Rasio rentabilitas}

Rasio rentabilitas menunjukan kemampuan PT. BPR. Saptacristy Utama dalam menghasilkan laba selama periode tertentu, juga bertujuan untuk mengukur tingkat efektifitas manajemen dalam menjalankan oprasional PT. BPR. Saptacristy Utama. Berdasarkan hasil perhitungan rasio rentabilitas PT. BPR. Saptacristy Utama dari tahun 2011 sampai dengan tahun 2015 dapat dilihat dari nilai net profit margin berkisar antara $19,25 \%$ sampai dengan $26,61 \%$, nilai dari return on asset berkisar antara $2,08 \%$ sampai dengan $3,70 \%$ dan nilai return on equity berkisar antara $14,10 \%$ sampai dengan $26,57 \%$. Hasil analisis terhadap rasio rentabilitas dapat dilihat pada Tabel 5. 
Tabel 5.

Perhitungan Analisis Rasio Keuangan Rentabilitas PT. BPR. Saptacristy Utama Tahun 2011 sampai dengan Tahun 2015

\begin{tabular}{|c|c|c|c|c|c|c|}
\hline \multirow{2}{*}{ Rasio Rentabilitas } & \multicolumn{5}{|c|}{ Tahun } & \multirow{2}{*}{$\begin{array}{c}\text { Rata- } \\
\text { rata }\end{array}$} \\
\hline & 2011 & 2012 & 2013 & 2014 & 2015 & \\
\hline Net Profit Margin & $\begin{array}{l}19,65 \% \\
\text { (Sehat) }\end{array}$ & $\begin{array}{c}23,36 \% \\
\text { (Sehat) }\end{array}$ & $\begin{array}{l}26,61 \% \\
\text { (Sehat) }\end{array}$ & $\begin{array}{l}23,46 \% \\
\text { (Sehat) }\end{array}$ & $\begin{array}{l}21,22 \% \\
\text { (Sehat) }\end{array}$ & $\begin{array}{c}22,86 \% \\
\text { (Sehat) }\end{array}$ \\
\hline Return On Asset & $\begin{array}{l}2,08 \% \\
\text { (Sehat) }\end{array}$ & $\begin{array}{l}2,57 \% \\
\text { (Sehat) }\end{array}$ & $\begin{array}{l}3,70 \% \\
\text { (Sehat) }\end{array}$ & $\begin{array}{l}2,69 \% \\
\text { (Sehat) }\end{array}$ & $\begin{array}{l}2,33 \% \\
\text { (Sehat) }\end{array}$ & $\begin{array}{l}2,67 \% \\
\text { (Sehat) }\end{array}$ \\
\hline Return On Equity & $\begin{array}{l}14,10 \% \\
\text { (Sehat) }\end{array}$ & $\begin{array}{c}23,16 \% \\
\text { (Sehat) }\end{array}$ & $\begin{array}{c}26,57 \% \\
\text { (Sehat) }\end{array}$ & $\begin{array}{c}23,04 \% \\
\text { (Sehat) }\end{array}$ & $\begin{array}{l}20,41 \% \\
\text { (Sehat) }\end{array}$ & $\begin{array}{l}21,45 \% \\
\text { (Sehat) }\end{array}$ \\
\hline
\end{tabular}

Sumber : Diolah dari data primer (2016)

Selama lima tahun terakhir yaitu dari tahun 2011 sampai dengan tahun 2015 nilai net profit margin setiap tahunnya cenderung berfluktuatif. Meskipun berfluktuatif, kenaikan net profit margin lebih besar dari penurunannya. Hal tersebut dikarenakan peningkatan net income sebanding dengan peningkatan operating inccome, sehingga tingkat kemampuan BPR untuk menghasilkan net income sesuai dengan yang diharapkan.Kinerja PT. BPR. Saptacristy Utama dilihat dari rata-rata net profit margin pada tahun 2011 sampai dengan tahun 2015 sebesar 22,86\%. Pencapaian presentase nilai rata-rata tersebut berada pada kriteria net profit margin> 5\% (sehat). Hal ini dapat diartikan bahwa kemampuan PT. BPR. Saptacristy Utama dalam menghasilkan net income adalah setiap Rp. 100,00 operating income menghasilkan net income sebesar Rp.22,8

Selama lima tahun terakhir yaitu dari tahun 2011 sampai dengan tahun 2015 nilai return on asset setiap tahunnya cenderung berfluktuatif. Meskipun berfluktuatif, kenaikan return on asset lebih besar dari penurunannya. Hal tersebut dikarenakan peningkatan laba sebelum pajaksebanding dengan peningkatan total asset, sehingga tingkat kemampuan BPR untuk menghasilkan laba sebelum pajak sesuai dengan yang diharapkan.Kinerja PT. BPR. Saptacristy Utama dilihat dari rata-rata return on asset pada tahun 2011 sampai dengan tahun 2015 sebesar 2,67\%. Pencapaian presentase nilai rata-rata tersebut berada pada kriteria return on asset $>1,22 \%$ yang berarti sehat (SK DIR BI Nomor : 30/21/KEP/DIR). Hal ini dapat diartikan bahwa kemampuan PT. BPR. Saptacristy Utama dalam menghasilkan laba sebelum pajak adalah setiap Rp. 100,00 total asset menghasilkan laba sebelum pajak sebesar Rp.2,67.

Selama lima tahun terakhir yaitu dari tahun 2011 sampai dengan tahun 2015 nilai return on equity tahunnya cenderung berfluktuatif. Meskipun berfluktuatif, kenaikan return on equity lebih besar dari penurunannya. Hal tersebut dikarenakan peningkatan net income sebanding dengan peningkatan ekuitas, sehingga tingkat kemampuan BPR untuk menghasilkan net income sesuai dengan yang diharapkan.Kinerja PT. BPR. Saptacristy Utama dilihat dari rata-rata return on equity 
pada tahun 2011 sampai dengan tahun 2015 sebesar 21,45\%. Pencapaian presentase nilai rata-rata tersebut berada pada kriteria return on equity> $12,5 \%$ yang berarti sehat (Peraturan Bank Indonesia No.6/10/PBI/2004). Hal ini dapat diartikan bahwa kemampuan PT. BPR. Saptacristy Utama dalam menghasilkan net income dengan mengelola ekuitas adalah setiap Rp. 100,00 ekuitas menghasilkan net income sebesar Rp.21,45.

\section{Simpulan dan Saran}

\subsection{Simpulan}

Secara umum, kinerja keuangan PT. BPR. Saptacristy Utama selama lima tahun terakhir baik, dimana semua hasil perhitungan rasio sudah memenuhi standar oprasional penilaian kinerja dan kesehatan yang diterbitkan Bank Indonesia untuk BPR.

\subsection{Saran}

Berdasarkan hasil analisis, maka dapat disarankan kepada pihak PT. BPR. Saptacristy Utama diharapkan agar mempertahankan kinerja keuangannya dengan memperkuat kegiatan usahanya agar jumlah asset yang dimiliki semakin meningkat, jumlah penyaluran dana baik dalam bentuk kredit maupun penempatan dana pada bank lain semakin meningkat, pendapatan operasional dan laba yang diperoleh untuk tahun-tahun berikutnya semakin meningkat, dan meningkatkan promosi serta pelayanan kepada para nasabah dan calon nasabah.

\section{Ucapan Terima Kasih}

Terima kasih kepada seluruh pihak yang telah memberikan pengarahan, bmbingan dan juga dukungan dalam penyelesaian penelitian dan penulisan ejurnalini. Semoga penelitian ini dapat bermanfaat sebagaimana mestinya.

\section{DaftarPustaka}

Bank Indonesia. 1998. UU No. 10 tahun 1998, tentang perubahan terhadap UU No. 7 tahun 1992, Jakarta.

Bank Indonesia. 2004. Peraturan Bank Indonesia No.6/10/PBI tentang Sistem Penilaian Tingkat Kesehatan Bank Umum, 12 April 2004. Jakarta: Bank Indonesia

Bank Indonesia. 1997. SK DIR Bank Indonesia No. 30/12/KEP/DIR. Tata Cara Penilaian Tingkat Kesehatan Bank Perkreditan Rakyat. Jakarta: Bank Indonesia.

Handayani, et al. 2012. Analisis Kinerja Keuangan berdarsarkan RasioProfitabilitas pada PT. Bhimex Di Samarinda.

Kasmir. 2004. Analisis Laporan Keuangan, Edisi Pertama. Rajawali Pers. Jakarta.

Kasmir. 2014. Manajemen Perbankan, Edisi Revisi. Rajawali Pers. Jakarta.

Ottay, Maikel Ch dan Stanly W. Alexander. 2015. Analisis Laporan Keuangan untuk Menilai Kinerja Keuangan pada PT. BPR. Citra Dumoga Manado. Jurnal 
EMBA. (Online), Vol. 3, No. 1, http://ejournal.unsrat.ac.id (diakses 4 Desember 2016).

Ramenayanthi, Komang Tri, I Ketut Suamba, dan I Nyoman Gede Ustriyana. 2016. Kinerja Keuangan KUD Mambal di Kecamatan Abiansemal, Kabupaten Badung. E-Jurnal Agribisnis dan Agrowisata. (Online), Vol. 5, No. 1, http://ojs.unud.ac.id/index.php/JAA/article/view/18636 (diakses 4 Desember 2016).

Sawir, Agnes. 2003. Analisis Kinerja Keuangan dan Perencanaan Keuangan Perusahaan. Penerbit PT. Gramedia Pustaka Utama. Jakarta.

Tim Pedoman Akuntansi Bank Perkreditan Rakyat Bank Indonesia. 2010. Pedoman Akuntansi Bank Perkreditan Rakyat. Jakarta, Ikatan Akuntan Indonesia (IAI). 